Araştırma Makalesi - Research Article

\title{
OECD Ülkelerinde Sosyal Güvenlik Harcamalarının Ekonomik Büyümeye Etkisinin Dinamik Panel Veri Analizi ile İncelenmesi
}

\section{Analysis of the Effects of Social Security Expenditures on Economic Growth in OECD Countries using Dynamic Panel Data Methods}

\author{
Murat BIINAY* \\ (iD) 0000-0002-9987-1492
}

\author{
Sosyal Güvenlik Dergisi / Journal of Social Security \\ Cilt: 11 Say1: 2 Y1l: 2021 / Volume: 11 Issue: 2 Year: 2021 \\ Sayfa Aralığı: 414-422 / Pages: 414-422 \\ DOI: $10.32331 /$ sgd.1049488
}

\section{ÖZ}

Sosyal güvenlik harcamalarının ekonomik büyüme üzerindeki etkisi iktisattaki ekonomik yaklaşımlara göre değişmektedir. Sosyal güvenlik harcamalarının ekonomik büyümeye etkisine yönelik iki farklı yaklaşım bulunmaktadır. Sosyal güvenlik harcamaları kamu harcaması olduğu için klasiklere göre artışı dışlama etkisiyle büyümeyi negatif etkiler. Keynesyen yaklaşıma göre ise bu tür harcamalardaki artış çarpan etkisiyle ekonomik büyümeyi artıracaktır. Literatürde her iki görüşü de doğrulayan ampirik çalışmalar mevcuttur. $\mathrm{Bu}$ çalışmada OECD ülkeleri ekonomisinde sosyal güvenlik harcamaları, sermaye birikimi, toplam faktör verimliliği (TFV) ve demokrasi endeksinin iktisadi büyüme üzerine etkileri, 1990- 2017 dönemi ve dengeli panel olması için eşit sayıda veriye sahip 22 ülke için incelenmektedir. Çalışma sonucunda toplam faktör verimliliğindeki artışın ve fiziki sermaye stokundaki artışın literatüre uygun şekilde ekonomik büyümeyi artırdığı görülmüştür. Sosyal güvenlik harcamalarının milli gelire oranı arttığında milli gelirin arttığı görülmüştür.

Anahtar Sözcükler: Ekonomik büyüme, GMM yöntemi

\section{ABSTRACT}

The impact of social security expenditures on economic growth varies according to economic approaches in economics. There are two different approaches to the effect of social security spending on economic growth. Since social security expenditures are public expenditures, they affect growth negatively with the effect of excluding increase compared to the classical ones. According to the Keynesian approach, an increase in such expenditures will increase economic growth with the multiplier effect. There are empirical studies in the literature confirming both views.In this study, the effects of social security expenditures, capital accumulation, total factor productivity (TFP) and democracy index on economic growth in the economy of OECD countries are examined for the period of 1990-2017 and 22 countries with equal numbers of data to be a balanced panel. As a result of the study, both total factor productivity and fixed capital stock inrease make the national income increase in the way appropriate to the literature. When the ratio of social security expenditures to national income increases national income increases too.

Keywords: Economic growth, GMM method

Önerilen atıf şekli: Binay, M. (2021). OECD Ülkelerinde Sosyal Güvenlik Harcamalarının Ekonomik Büyümeye Etkisinin Dinamik Panel Veri Analizi ile İncelenmesi. Sosyal Güvenlik Dergisi (Journal of Social Security). 11(2). 414-422.

- Geliş Tarihi/Received: 29/01/2021 • Güncelleme Tarihi/Revised: 13/09/2021 • Kabul Tarihi/Accepted: 27/12/2021 


\section{GíRIŞ}

Sosyal güvenlik sistemi, sosyal ve ekonomik yönden riskler ile karşı karşıya kalan bireylere sağlamış olduğu güvenceden ötürü ekonomiyi mikro ve makro yönden etkilemektedir. Mikro düzeyde bu etkiler kişinin çeşitli tehlikelere karşı korunmasını ele alırken, makro düzeyde gelir dağılımı fiyat istikrarı tasarruf, istihdam, bütçe dengesi büyüme ve kamu borçları üzerine odaklanmaktadır. Sosyal güvenlik harcamaları ile ekonominin makro değişkenleri arasında bahse konu ülkenin işgücü piyasasının yapısına, sosyal güvenlik sisteminin finansman yapısı ve tekniğine ve demografik özelliklerine göre değişen ilişki bulunmaktadır. Bu sebeple literatürde sosyal güvenlik harcamalarının ekonomi üzerinde hem olumlu hem de olumsuz etkilerinin olduğuna dair çalışmalar bulunmaktadır.

Sosyal güvenlik harcamalarının ekonomik büyüme üzerindeki etkisi iktisattaki ekonomik yaklaşımlara göre değişmektedir. Klasik iktisat okulu dışlama etkisi sebebiyle sosyal güvenlik harcamalarındaki bir artışın milli gelir üzerinde bir etki yaratmadığını savunmaktadır. Keynesyen ekonomik yaklaşıma göre ise sosyal güvenlik harcamaları, kamu harcamalarının bir alt bileşeni olduğundan bu tür harcamalardaki bir artış çarpan etkisine bağlı olarak ulusal geliri artırmaktadır (Baylan, 2014, s.32).

Bu çalışmada sosyal güvenlik harcamalarının ekonomik büyümeye etkisi dinamik panel veri analiz yöntemleri ile analiz edilecektir.

\section{I- TEORIKK ÇERÇEVE VE ALAN TARAMASI}

Yılmaz, Özer ve Gümüşsoy Türkiye için beşerî sermaye ile iktisadi büyüme arasındaki ilişkiyi 1978- 2014 arası yıllık verileri kullanılarak analiz etmiştir. Beşerî sermaye ile iktisadi büyüme arasındaki uzun dönemli ilişki Gecikmesi Dağıtılmış Otoregresif Sınır Testi ile sınanmış ve uzun dönemde beşerî sermayenin iktisadi büyümeyi pozitif etkilediği sonucuna ulaşılmıştır.

Kamac1, Ceyhan ve Peçe'ye göre toplam faktör verimliliği uzun dönemli ekonomik büyümenin en önemli etkenidir. Sermaye ve emek sabit kaldığı durumda, gelir düzeyinin artması, toplam faktör verimliliğinin artması ile mümkündür. Geri kalmış ülkelerin toplam faktör verimliliği düşük, zengin ve gelişmiş ülkelerin ise toplam faktör verimliliği yüksektir. Bahse konu çalışmada 15 OECD ülkesinde nedensel ilişki toplam faktör verimliliğinden iktisadi büyümeye doğru tek yönlü olup, Parks - Kmenta tahmin edicisine göre toplam faktör verimliliğindeki bir birimlik artışın iktisadi büyümeyi 1, 19 birim artırdığı tespit edilmiştir.

Söylemez ve Yurttançıkmaz'ın çalışmasında Türkiye'de, beşeri sermayenin, sağlık ve eğitim bileşenleri ile fiziki sermayenin ekonomik büyüme üzerindeki etkisi Granger nedensellik testi, Johansen eşbütünleşme testi ve VEC yöntemleri ile test edilmiş ve hem kısa dönem hem de uzun dönemde kişi başı eğitim harcamaları ve sabit sermaye yatırımlarının iktisadi büyümeyi artırdığı tespit edilmiştir. Granger nedensellik testi sonuçlarına göre ekonomik büyüme ve kişi başına sabit sermaye yatırımlarının kişi başı eğitim harcamalarını artırdığı; ayrıca kişi başı sağlık harcamalarının kişi başı eğitim harcamalarını artırdığı tespit etmiştir.

Kırıkçı \& Yanar faktörler perspektifi ile beşerî sermaye ve iktisadi büyüme ilişkisini gelişmekte olan ve gelişmiş ülkeler ayrımı ile incelemiştir. Gelişmiş ülkelerde sağlık, eğitim, hukuksal yapı, demokrasi yolsuzluğun engellenmesi ile iktisadi büyümenin arttığı; gelişmekte olan ülkelerde ise, sağlık harcamaları, eğitim ve yolsuzluğun önlenmesi ile iktisadi büyüme arasında pozitif ilişki bulunmasına rağmen, hukuksal yapı ve demokrasi arasında anlamlı bir ilişki tespit edilememiştir. 
Alper (2019) finansal gelişme, enflasyon, ticari ve finansal açıklığın Türkiye'nin ekonomik büyümesine etkileri 1974 - 2017 dönemi boyunca incelenmiştir. Fourier - Shin (FSHIN) eşbütünleşme testinin yapıldığı çalışma, eşbütünleştirilmiş serilerin varlığını tespit etmiştir. Uzun vadeli katsayıların tahminine dayanan dinamik sıradan en küçük kareler (DOLS) ve sıradan en küçük kareler (FMOLS) yöntemlerine göre, finansal gelişmenin finansal büyümeyi ve ticari açıklığı ve ekonomik büyümeyi olumlu etkilediği belirlenmiştir, enflasyonun ise olumsuz etkileri olduğu tespit edilmiştir.

Demokrasinin ülkelerin iktisadi büyümeye etkilerine dair çalı̧̧malar 1990'lı yıllardan sonra hız kazanmıştır. Rodrik (2000), demokrasi ile iktisadi büyüme arasındaki ilişkiyi 90 ülke için 1970-1989 arası dönem için araştırmıştır. Freedom House'un sivil özgürlükler ve politik haklar endekslerinin kullanıldığı çalışmaya göre katılımcı demokrasilerde kaliteli (gelir dağılımının adil olduğu) iktisadi büyümenin elde edildiği sonucuna ulaşılmıştır. Çalışmaya göre katılımcı demokrasilerde gelir dağılımında eşitliğin sağlandığı şoklara karşı dayanıklı, öngörülebilir ve istikrarlı, yüksek kaliteli bir büyüme ortaya çıkar.

Wacziarg ve Tavares 2001 yılında yaptıkları çalışmalarında, iktisadi büyüme ve demokrasi arasındaki ilişkiyi yine 1970 ve 1989 yılları arası dönemi kapsayacak şekilde incelemiş, demokrasinin beşeri sermaye birikimini arttırarak ve gelir eşitsizliğini azaltarak ve iktisadi büyümeyi artırıcı yönü bulunmakla beraber, fiziki sermaye birikimi sağlayan yatırımları düşürerek ve kamu tüketim harcamalarının milli gelire oranını yükselterek de büyümeyi engellediği sonucuna varmıştır. Sonuç olarak demokrasinin iktisadi büyüme üzerindeki toplam etkisi negatif ve orta düzey çıkmıştır. Yay tarafından 2002 yılında gerçekleştirilen ve yine Freedom House'dan elde edilen sivil özgürlükler ve politik haklar endeksini kullanarak yapılan bir başka çalışmada ise ekonomik büyüme ile demokrasi ile arasında anlamlı bir ilişki ortaya çıkmamıştır.

Doucouliagos ve Ulubaşoğlu'nun 2004 yılında yaptığı çalışmada politik özgürlük endeksi ile iktisadi büyüme arasındaki ilişkiyi araştırılmış, politik özgürlüklerin beşeri sermaye birikimi ve toplam faktör verimliliği üzerindeki etkisinin pozitif, fakat işgücü büyümesi ve fiziki sermaye birikimi ve üzerindeki etkisinin negatif olduğu Sonucuna ulaşılmıştır.

Sosyal güvenlik harcamalarının ekonomik büyümeye etkisine dair iki farklı yaklaşım bulunmaktadır. Sosyal güvenlik harcamaları kamu harcaması olduğu için klasiklere göre artışı dışlama etkisiyle büyümeyi negatif etkiler. Keynesyen yaklaşıma göre ise çarpan etkisiyle bu tür harcamalardaki artışın ekonomik büyümeyi artırması beklenmektedir. Literatürde her iki görüşü de destekleyen çalışmalar bulunmaktadır. Bräuninger'e göre sosyal güvenlik harcamaları özel tasarrufları azaltır ve dolayısıyla büyümeyi düşürür (Bräuninger, 1996: 226 - 235). Bu duruma neden olan birinci sebep, işsizlik oranının artması ile işsizlik sigorta primlerinde de artış gerçekleşir ve bu artışın çalışanların net gelirini düşürmesi ile de tasarruflarda düşüşe sebep olmasıdır. Tasarruflardaki düşüşün diğer sebebi bireyin tüketim harcamaları kısmen de olsa sosyal güvenlik tarafından finanse edildiği için emekli gelirindeki tasarruf güdüsünün düşmesidir. İkinci sebep ise yaşlıların nüfus içindeki oranının artmasının sosyal güvenliğin harcamalarının çalışanlar üstündeki yükü artırmasıdır. Sonuç olarak sosyal güvenlik harcamalarındaki artışın tasarrufları azaltarak sermaye birikiminin oluşmasına engel olduğu yönde çalışmalar da mevcuttur (Thøgersen, 2009: 3; Bräuninger, 2004: 14; Bräuninger, 1996: 234).

Sosyal güvenlik harcamalarının iktisadi büyümeyi artırdığına dair çalışmalar da mevcuttur. Lee ve Chang (2006), OECD ülkelerinde milli gelir ile sosyal güvenlik harcamaları nedensellik ilişkisini analiz ettiği çalışmada, sosyal güvenlik harcamaları ile GSYİH arasındaki ilişkinin uzun vadede eş bütünleşik ve çift yönlü olduğunu; kısa vadede ise aralarında nedensellik ilişkisi bulunmadığını tespit etmiştir.. Lee ve Chang'e göre, OECD 
ülkelerinde sosyal güvenlik harcamaları ekonomik büyümeyi beşerî sermaye birikimi ve tasarruflar aracılığ ile artırmaktadır (Lee ve Chang, 2006:1).

Özetle, fiziki sermaye birikimi, toplam faktör verimliliğinin ekonomik büyümeyi pozitif yönde etkilediği literatürde neredeyse genel kabul görürken; demokrasi ve sosyal güvenlik harcamalarının ekonomik büyümeye etkisinin beşeri sermaye birikimini arttırarak ve gelir eşitsizliğini azaltarak büyümeyi artırıcı etkisinin yanında, kamu tüketim harcamalarının GSYH'ya oranını yükselterek ve fiziki sermaye birikimini engelleyerek ve büyümeyi düşürücü iki zıt etkisinin olduğu düşünülmektedir.

Dolayısıyla bu çalışmada ekonomik büyüme üzerinde etkisi literatürde tartışmalı olmasına rağmen beşeri sermayeyi artırarak ekonomik büyümeyi artıracağı düşünülen bu iki değişken de modele eklenecek ve ekonomik büyümenin ana unsurları kabul edilen fiziki sermaye birikimi ve toplam faktör verimliliği yanında ekonomik büyümeye ne kadar katkısı olduğu analiz edilmiştir.

\section{II- METODOLOJI}

Çalışmada 22 OECD ülkesine ait 1990-2017 dönemine ait veriler kullanılarak sosyal güvenlik harcamalarının iktisadi büyüme üzerindeki etkisi dengeli panel analiz ile araştırılmıştır.

Çalışmada dinamik panel veri analiz yöntemi kullanılmaktadır. Dinamik panel veri analizinin gözlem sayısının fazlalığı ve daha homojen yapı sağlaması, serbestlik derecesini artırarak açıklayıcı değişkenler arasında bağlantı sorununu azaltma gibi avantajları bulunmaktadır.

Ayrıca dinamik panel veri analizinin otokorelasyon, değişen varyans ve içsellik sorunu ve gibi durumlarda daha etkin sonuçlar verebilmektedir. İki kademeli sistem genelleştirilmiş momentler (two-step Sistem-GMM) yöntemi dinamik panel veri analizinde de daha güçlü sonuçlar vermektedir (Hayaloğlu ve Topal, 2017: 199). Çünkü modele bağımsız değişken olarak bağımlı değişkenin gecikmeli değeri dahil edilmekte ve meydana çıkabilecek içsellik sorunu baştan giderilebilmektedir.

Arellano ve Bond (1991) tarafindan geliştirilen fark GMM'de, dinamik panel tahmininde oluşabilecek aksaklıklar, araç değişkeni olarak bağımlı değişkenin önceki dönem değerlerini kullanarak ve değişkenlerin birinci dereceden farklarını alıp modele dahil edilerek giderilebilmektedir. Sistem GMM panel veri analizi ise zaman boyutu (T) birim boyutu (N)'den küçük olduğunda kullanılmakta olup, modele daha fazla araç değişken dahil edilerek modelin verimliliği artırılmaktadır (Hayaloğlu ve Topal, 2017: 199).

$\mathrm{Bu}$ çalışmada OECD ülkeleri ekonomisinde sosyal güvenlik harcamaları, sermaye birikimi, toplam faktör verimliliği (TFV) ve demokrasi endeksinin iktisadi büyüme üzerine etkileri, 1990- 2017 dönemi ve dengeli panel olması için eşit sayıda veriye sahip 22 ülke için incelenmektedir.

\section{III- MODEL VE VERI SETI}

Sosyal güvenlik harcamaları ile ekonomik büyüme ve ekonomik büyümenin diğer bileşenlerini arasındaki ilişkiyi dinamik panel veri ile analiz etmek için oluşturulan ekonometrik model aşağıdadır:

$$
G \mathrm{SH}_{i t}=\alpha+\beta_{1} \mathrm{DEM}_{\mathrm{it}-1}+\beta_{2} \mathrm{SH} i t+\beta_{3} \mathrm{DEMit}+\beta_{4} \mathrm{TFVit}+\beta_{5} \mathrm{FSit}+\mu_{\mathrm{i}}+\mathrm{u}_{\mathrm{it}}
$$

Modelde t zamanı, i ülkeyi; $\alpha$ sabit terimi; $\beta$ 'lar eğim katsayılarını; $\mu$ birim etkiyi ve $u$ hata terimini ifade etmektedir. İktisadi büyüme oranını gösteren $G \mathrm{SH}$ bağımlı değişkendir. SH ana 
bağımsız değișken olup sosyal güvenlik harcamalarının milli gelire oranını ifade ederken, diğer değişkenler ekonomik büyüme üzerinde etkisi olan kontrol değişkenleridir. TVF Toplam Faktör Verimliliği, FS fiziki sermaye stokunun milli gelire oranıdır.

Denklem (1)'de kişi başına düşen milli gelirin büyüme oranı, sosyal güvenlik harcamalarını milli gelire oranı ve ekonomik büyümenin temel bileşenleri olan fiziki sermaye stokunun milli gelire oranı, toplam faktör verimliliği ve demokrasi endeksi üzerinden modellenmiştir.

Bu çalışmada sosyal güvenlik harcamalarının ile ekonomik büyüme (milli gelir artış hızı) arasındaki ilişki 22 OECD ülkesi (Kanada, İngiltere, Avustralya, Belçika, Yeni Zelanda Avusturya, Danimarka, Finlandiya, İrlanda, Yunanistan, Almanya, Macaristan İzlanda, Japonya, Kore, Hollanda, İsviçre, Norveç, İtalya, İspanya, İsveç ve ABD) için 1990- 2017 dönemi yıllık verileri kullanılarak analiz edilmiştir.

Veriler 2011 yılı baz alınarak milyon ABD doları olarak ifade edilen seri Penn World Table 9,1'den, OECD Stat'tan ve Polity IV'den alınmıştır. Veri analizleri Stata 15 ve Gauss 20 bilgisayar programları aracılığıyla gerçekleştirilmiştir.

Dengeli panel analizini sağlamak için 22 ülkenin de eşit sayıda veriye sahip olma şartı dikkate alınmış ve 1990-2017 dönemi 28 senelik veri ile 22 ülkeden 616 adet gözlem değeri elde edilmiştir.

Tablo 1. Değişkenler ve Veri Kaynakları

\begin{tabular}{lll}
\hline Değişkenler & Açılama & Veri Kaynakları \\
\hline GSH & $\begin{array}{l}\text { GSYH Büyüme } \\
\text { Oranı-\% değişim (2010 Sabit } \\
\text { Fiyatlarıyla ABD \$ cinsinden) }\end{array}$ & Penn World Table 9,1 \\
\hline SH & $\begin{array}{l}\text { Sosyal güvenlik harcamalarının milli gelire } \\
\text { oranı }\end{array}$ & OECD Stat \\
\hline FS & $\begin{array}{l}\text { Gayri Safi Sabit Sermaye } \\
\text { Oluşumu (\% GSYİH) }\end{array}$ & (World Development \\
\hline TFV & Toplam Faktör Verimliliği & Penn World Table 9,1 \\
\hline DEM & Demokrasi Endeksi & Polity IV \\
\hline
\end{tabular}

\section{A- SAGP'ne Göre Reel GSYIH}

Bağımlı değişken olarak ekonomik büyüme, cari satın alma gücü paritesine göre harcamalar yöntemiyle elde edilen reel GSYİH (SAGP) olarak modele dahil edilmiştir. Seri 2011 yılı baz alınarak milyon ABD doları olarak ifade edilmektedir. Söz konusu seri Penn World Table 9,1'den (PWT) alınmıştır. "SAGP farklı para birimlerinin satın alma güçlerini, ülkeler arasındaki fiyat düzeyi farklılıklarını ortadan kaldırarak eşitleyen bir değişıim oranını ifade etmektedir" (Eğilmez, 2017). Dolayısıyla ülkeler arasındaki fiyat farklılıklarını dikkate alarak ülkelerin ekonomik anlamda karşılaştırılmasına imkân tanır. Nitekim birçok ekonomist SAGP kullanılmasının daha uygun olacağını savunmaktadırlar (Reinert vd., 2009:942). Bu çalışmada SAGP' ye göre veriler seçilerek sapma önlenmiştir.

\section{B- Toplam Faktör Verimliliği (TFV) Endeksi}

TFV endeksi, sadece emek ve sermaye faktörlerinin değil üretimde kullanılan tüm faktörlerin birlikte kullanıldığ 1 bir üretim sürecindeki mevcut verimliliği ifade etmektedir. TFV' deki 
büyüme hızı, GSYH'de emek ve sermaye girdilerindeki dışında kalan faktörlerdeki artışları göstermektedir. Bu yönüyle uzun vadede sürdürülebilir ekonomik büyümenin temel kaynağı olarak nitelendirilebilmektedir.

\section{C- SAGP'ne Göre Sosyal Güvenlik Harcamaları}

Sosyal güvenlik harcamalarının ekonomik büyümeye etkisine dair iki farklı yaklaşım bulunmaktadır. Sosyal güvenlik harcamaları kamu harcaması olduğu için klasiklere göre artışı dışlama etkisiyle büyümeyi negatif etkiler. Keynesyen yaklaşıma göre ise çarpan etkisiyle bu tür harcamalardaki artışın ekonomik büyümeyi artırması beklenmektedir. Literatürde her iki görüşü de destekleyen çalışmalar bulunmaktadır. SAGP' ne Göre Sosyal Güvenlik Harcamaları verileri OECD Stat'dan temin edilmiştir.

\section{IV- EKONOMETRİK METODOLOJI}

Çalışmada ekonomik büyüme faktörlerinin ekonomik büyüme üzerindeki etkisi analiz edilmektedir. Modelde kullanılacak değişkenlere ait tanımlayıcı istatistiklere Tablo 2 de yer verilmiştir. Ardından Tablo 3'de bağımsız değişkenlerin ekonomik büyüme ile korelasyonuna bakılmıştır.

Tablo 2. Tanımlayıcı Ístatistikler

\begin{tabular}{lllll}
\hline Değișkenler & Ortalama & Standart Sapma & Min. & Max. \\
\hline GSH & 2.132 & 2.849 & -9.132 & 11.113 \\
\hline FS & 22.307 & 3.577 & 11.544 & 35.672 \\
\hline TFV & 0.9881078 & 0.0656487 & 0.7326 & 1.2124 \\
\hline DEM & 9.905844 & 0.3663464 & 8 & 10 \\
\hline SH & 8.695 & 2.026 & 3.998 & 16.516 \\
\hline Kaynak: Yazart
\end{tabular}

Kaynak: Yazarın Kendi Hesaplamaları

Tablo 3'de sosyal güvenlik harcamaları ve demokrasi endeksi başta olmak üzere fiziki sermaye stoku, toplam faktör verimliliği değişkenlerinin GSH üzerindeki etkisini belirleyebilmek için yapılan dört ayrı dinamik panel veri analiz sonuçları görülmektedir. Bu tahminler ekonomik büyümenin otoregresif katsayısı için alt ve üst sınırları gösterdikleri için faydalıdir. (Bond, 2002).

Sabit etkiler tahmin edicisi alt sınırı verirken Havuzlamış EKK tahmin edicisi üst sınırı vermektedir. Buna durumda üst sınır 0.235, alt sınır 0.181'dir. Her iki değer de istatistiksel olarak \%1 düzeyinde anlamlı ve pozitiftir. Havuzlanmış EKK tahmininde sosyal güvenlik harcamaları, fiziki sermaye stoku, toplam faktör verimliliği ve demokrasi endeksi istatistiksel olarak anlamlı bulunmamıştır, sadece olan gecikmeli ekonomik büyüme değişkeninin katsayısı (bağımlı değişkenin gecikmeli değeri) istatistiksel olarak anlamlı çıkmış olup; bağımlı değişken olan ekonomik büyümenin büyük ölçüde önceki dönemdeki ekonomik büyüme düzeyi tarafından belirlendiği ve sosyal güvenlik harcamalarının ekonomik büyüme üzerinde etkisi olmadığı şeklinde yorumlanabilir. Bunun yanında bu yöntemde, yöntemin birim ve zaman etkileri göz ardı etmesinden ve hata terimi ile bağımlı değişkenin gecikmeli değeri arasında korelasyonun olmasından dolayı parametre tahmincileri tutarsız ve sapmalı olmaktadir. 
Sabit etkiler yönteminde, gecikmeli ekonomik büyüme (bağımlı değişkenin gecikmeli değeri) haricindeki değişkenler istatistiksel olarak anlamsız çıkmıştır, gecikmeli bağımlı değişken ekonomik büyüme ise \%1 düzeyinde istatistiki olarak anlamlı çıkmıştır. Bu durum sosyal güvenlik harcamalarının ekonomik büyümeyi etkilemediği şeklinde açıklanabilir. Bununla beraber sabit etkiler yönteminde zaman boyutu (T) küçük olduğu ve gecikmeli bağımlı değişken ile hata teriminin korelasyonlu olmasına izin verildiği için analizde yine parametre tahminleri tutarsız ve sapmalıdır. Bu sorun araç değişkenlerin kullanılmasına imkan veren Genelleştirilmiş Momentler Metodu ile çözülmüştür.

Tablo 3. Dinamik Panel Veri Tahmin Sonuçları

\begin{tabular}{|c|c|c|c|c|}
\hline Değişkenler & Havuzlanmış EKK & Sabit Etki EKK & Fark-2 GMM & $\begin{array}{l}\text { Sistem-2 } \\
\text { GMM }\end{array}$ \\
\hline \multirow[t]{2}{*}{$G \operatorname{sh}(-1)$} & $\begin{array}{l}0.235^{*} \\
(12.68)\end{array}$ & $\begin{array}{l}0.281^{*} \\
(8.08)\end{array}$ & $\begin{array}{l}0.246^{*} \\
(11.17)\end{array}$ & $\begin{array}{l}0.204^{*} \\
(5.53)\end{array}$ \\
\hline & {$[0.000]$} & {$[0.000]$} & {$[0.000]$} & {$[0.000]$} \\
\hline $\mathrm{SH}$ & $\begin{array}{l}0.228 * \\
(5.12) \\
{[0.893]}\end{array}$ & $\begin{array}{l}0.181 * \\
(7.98) \\
{[0.992]}\end{array}$ & $\begin{array}{l}0.202 * \\
(7.99) \\
{[0.541]}\end{array}$ & $\begin{array}{l}0.202 * \\
(9.24) \\
{[0.002]}\end{array}$ \\
\hline FS & $\begin{array}{l}0.273^{*} \\
(5.75) \\
{[0.167]}\end{array}$ & $\begin{array}{l}0.288^{*} \\
(4.50) \\
{[0.523]}\end{array}$ & $\begin{array}{l}0.354 * \\
(6.76) \\
{[0.134]}\end{array}$ & $\begin{array}{l}0.230 * \\
(2.74) \\
{[0.003]}\end{array}$ \\
\hline TVF & $\begin{array}{l}0.364^{*} \\
(5.77) \\
{[0.691]}\end{array}$ & $\begin{array}{l}0.328 * \\
(10.09) \\
{[0.273]}\end{array}$ & $\begin{array}{l}0.356^{*} \\
(5.33) \\
{[0.262]}\end{array}$ & $\begin{array}{l}0.299 * \\
(4.14) \\
{[0.047]}\end{array}$ \\
\hline DEM & $\begin{array}{l}0.162^{*} \\
(7.33) \\
{[0.888]}\end{array}$ & $\begin{array}{l}0.081 * * * \\
(1.78) \\
{[0.853]}\end{array}$ & $\begin{array}{l}0.183 * \\
(3.40) \\
{[0.547]}\end{array}$ & $\begin{array}{l}0.149 * * \\
(2.18) \\
{[0.423]}\end{array}$ \\
\hline sabit & $\begin{array}{l}14.435^{*} \\
(6.03)\end{array}$ & $\begin{array}{l}12.538^{*} \\
(2.68)\end{array}$ & $\begin{array}{l}11.361 * \\
(3.11)\end{array}$ & $\begin{array}{l}14.303 * \\
(3.70)\end{array}$ \\
\hline Wald $\left(\chi^{2}\right)$ & $\begin{array}{l}3689.98 \\
{[0.000]}\end{array}$ & $\begin{array}{l}8092.05 \\
{[0.000]}\end{array}$ & $\begin{array}{l}3995.20 \\
{[0.000]}\end{array}$ & $\begin{array}{l}1375.25 \\
{[0.000]}\end{array}$ \\
\hline Sargan $\left(\chi^{2}\right)$ & $\begin{array}{l}19.798 \\
{[0.839]}\end{array}$ & $\begin{array}{l}18.008 \\
{[0.903]}\end{array}$ & $\begin{array}{l}20.912 \\
{[0.790]}\end{array}$ & $\begin{array}{l}19.566 \\
{[0.848]}\end{array}$ \\
\hline $\operatorname{AR}(1)$ & $\begin{array}{l}-3.334 \\
{[0.000]}\end{array}$ & $\begin{array}{l}-3.199 \\
{[0.001]}\end{array}$ & $\begin{array}{l}-3.301 \\
{[0.001]} \\
\end{array}$ & $\begin{array}{l}-3.288 \\
{[0.001]}\end{array}$ \\
\hline $\mathrm{AR}(2)$ & $\begin{array}{l}1.623 \\
{[0.104]}\end{array}$ & $\begin{array}{l}1.516 \\
{[0.129]} \\
\end{array}$ & $\begin{array}{l}1.644 \\
{[0.100]}\end{array}$ & $\begin{array}{l}1.570 \\
{[0.116]}\end{array}$ \\
\hline Hansen Test & & & $9.12[0.764]$ & $6.19[0.906]$ \\
\hline Fark Hansen & & & $0.19[0.996]$ & $1.37[0.242]$ \\
\hline $\mathrm{R}^{2}$ & 0.94 & 0.98 & & \\
\hline Ülke sayısı & 22 & 22 & 22 & 22 \\
\hline Gözlem sayısı & 616 & 616 & 616 & 616 \\
\hline Araç Sayısı & & & 16 & 15 \\
\hline
\end{tabular}

\section{Kaynak: Yazarın Kendi Hesaplamaları}

Not: Bütün analizlerde sağlam (robust) standart hatalar kullanılmış olup köşeli parantez içindeki sayılar olasılık değerleri, parantez içindeki sayılar standart hataları göstermektedir. ***, ** ve * işaretleri, $\% 1, \% 5$ ve $\% 10$ düzeylerinde istatistiksel anlamlılı̆̆ 1 göstermektedir. 
Tek aşamalı GMM tahmin edicilerinin heteroskedasite ve otokorelasyon sorunlarını düzeltmek için iki aşamalı GMM modelleri tercih edilmektedir (Tatoğlu, 2018:134). Fark GMM tahmin sonuçları tablonun 3. sütununda görülmektedir. 1. ve 2. sütunlarda gösterilen alt ve üst sınırlar içinde olmayan otoregresif katsayı \%1 düzeyinde istatistiki olarak anlamlı bulunmuştur. Diğer değişkenler istatistiki olarak anlamlı bulunmamıştır.

4. sütunda iki aşamalı sistem GMM sonuçları görülmekte olup Wald test istatistiği ile sistem GMM yönteminin geçerliliğini ve anlamlılığı sorgulanmıştır. Sargan ve Hansen test istatistikleri ise araç değişkenlerin geçerli olup olmadığ 1 ; $A R(1)$ ve $A R(2)$ testleri ile ise modelde birinci ve ikinci dereceden otokorelasyon bulunup bulunmadığ sorgulanmıştır. Model, Wald test istatistiğine göre \%1 düzeyinde istatistiki olarak anlamlı bulunmuştur. Modelde birinci derece ya da ikinci derece otokorelasyon problemi bulunmamaktadır. Sargan ve Hansen testi ile de kullanılan araç değişkenlerin geçerli olduğu tespit edilmiştir. Fark Hansen testi de içsellik sorunu olmadığını göstermiştir. Dolayısıyla sistem GMM kullanmak için gerekli varsayımlar sağlanmıştır.

Sistem GMM kullanarak tahmin edilen katsayılar incelendiğinde ise iktisadi büyümenin en önemli faktörünün toplam faktör verimliliği olduğu görülmektedir. Sosyal güvenlik harcamalarının milli gelire oranı \%1 arttığında ekonomik büyüme oranı 0.202 artmaktadır. $\mathrm{Bu}$ literatürdeki Keynesyen görüşe ve beşeri sermayeye dayalı içsel ekonomik büyüme modeline uygundur. Demokrasi endeksinin ekonomik büyümeye etkisi ise 0.149 ile en düşük faktör olarak kalmıştır.

\section{SONUC}

Bu çalışmada, 22 OECD ülkesinde 1990-2017 dönemindeki sosyal güvenlik harcamaları ve demokrasi endeksi ile ekonomik büyüme arasındaki ilişki dinamik panel veri metodolojisinde önemli bir yeri olan sistem GMM tekniği ile araştırılmıştır.

Çalışmanın sonuçları sosyal güvenlik harcamaları, fiziki sermaye stoku, toplam faktör verimliliği ve demokrasi endeksi ile GSH arasında pozitif bir ilişkinin varlığını tespit etmiştir.

Panel Granger nedensellik sonuçlarına göre ise sosyal güvenlik harcamaları, sermaye stoku ve toplam faktör verimliliği GSH'ın Granger nedenidir. Demokrasiden GSH'e doğru herhangi bir nedensellik tespit edilememiştir.

Bu sonuçlar, uzun dönemde sosyal güvenlik harcamaları ve demokrasi endeksinin OECD ülkelerinde GSH'ın belirleyicileri arasında olduğunu kanıtlar niteliktedir.

Ayrıca ekonomik büyümeyi etkileyen faktörlerin de OECD ülkeleri için bir anlamda sıralaması yapılmış ve sırasıyla toplam faktör verimliliği, sosyal güvenlik harcamaları, fiziki sermaye stoku ve demokrasi endeksinin ekonomik büyüme hızını artırdığı tespit edilmiştir. 


\section{Kaynakça}

Alper, F. (2019). Determinants of Economic Growth: The Case of Turkey Under Structural Breaks

Fiscaoeconomia, 3(1). $202-227$.

Arellano, Manuel. Panel Data Econometrics, England: Oxford University Press. 2003.

Baylan, M. (2015). Sosyal Güvenlik Harcamalarının Makroekonomik Etkileri: Bir Literatür Taraması.

Kahramanmaraş Sütçü İmam Üniversitesi Sosyal Bilimler Dergisi. 12 (1).

Brauninger, M. (1996). Capital Accumulation Under A Pay-As-You-Go Social Security: The Influence Of Labour Growth. International Journal of Social Economics. 23(10-11). MCB University Press. 226235.

Çınar, S. ve Özçalık, M. (2014). Gelişmekte Olan Ülkelerde Mali Sürdürülebilirlik: Panel Veri Analizi. Journal of Yasar University. 9(33).

Eğilmez, M. (2017). [http://www.mahfiegilmez.com/2017/08/turkiye-ekonomisi-dunyada-kacincisrada.html]. (Erişim: 02 Temmuz 2020).

Fuchs V. Economics, Values, and Healthcare Reform. Am Econ Rev. 1996. 86(1). 1-24.

Gujarati, Damodar. N. ve Porter, Dawn. C. Temel Ekonometri, Çev. Ümit Şenesen ve Gülay Günlük Şenesen, İstanbul: Literatür Yayıncılık. 2014.

Kamac1, A., Ceyhan, S. ve Peçe, M. (2019). Toplam Faktör Verimliliğinin Ekonomik Büyümeye Etkisi: 15 OECD

Ülkesi İçin Panel Veri Analizi. Artvin Çoruh Üniversitesi Uluslararası Sosyal Bilimler Dergisi. 5 (1). 22-36.

Kırıkçı, M. B. ve Yanar, R. (2020). Kurumsal Yapı, Beşerî Sermaye ve Ekonomik Büyüme İlişkisi: Gelişmiş ve Gelişmekte Olan Ülkeler İçin Panel Veri Analizi. Gaziantep University Journal of Social Sciences. 19(2). 311331.

Reinert, K. A., Rajan, R. S., Glass, A. J., ve Davis, L. S. (Eds.). (2009). The Princeton Encyclopedia of the World Economy. (Vol. 1). Princeton University Press.

Rodrik, Dani (2000), "Institutions for High Quality Growth: What They are and How to Acquire Them". National Bureau of Economic Research, Working Paper 7540.

Söylemez, A. ve Yurttançıkmaz, Z. Ç. (2020). Beşerî Sermayenin Ekonomik Büyüme Üzerindeki Etkisi: Türkiye Üzerine Bir İnceleme. Journal of Graduate School of Social Sciences. 24(1). 175-195.

Topal, Mehmet Hanefi ve Hayaloğlu, Pınar. "Farklı Gelişmişlik Düzeylerinde Kurumsal Kalitenin Çevre Performansı Üzerindeki Etkisi: Ampirik Bir Analiz”. Sosyoekonomi. 25(32). 2017. 189-212.

Ulubaşoğlu, Mehmet A. ve Doucouliagos, Chris (2004). Institutions and Economic Growth: A Systems Approach. Econometric Society 2004. Australasian Meetings Paper No. 63.

Yılmaz, Ö. ve Gümüşsoy. (2019). The Impact of Human Capital on Economic Growth in Turkey: Autoregressive Distributed Lag Approach. Optimum Ekonomi ve Yönetim Bilimleri Dergisi. 6(1). 1- 16.

Yerdelen Tatoğlu, F. (2012). İleri Panel Veri Analizi. İstanbul. Beta Basım A.Ş. 2. bs. 